\title{
Optimization of Large Passenger Aircraft Supply Chain Resilience Based on Bilateral Grey Quality Function Deployment considering Cooperation Uncertainty
}

\author{
He-Hua Wang (D), ${ }^{1}$ Ya Luo, ${ }^{2}$ and Jian-Jun $\mathrm{Zhu}^{2}$ \\ ${ }^{1}$ Jinling Institute of Technology, Nanjing, Jiangsu 211169, China \\ ${ }^{2}$ College of Economics and Management, Nanjing University of Aeronautics and Astronautics, Nanjing, Jiangsu 211106, China
}

Correspondence should be addressed to He-Hua Wang; whh@jit.edu.cn

Received 25 September 2021; Accepted 17 January 2022; Published 27 February 2022

Academic Editor: Francesco Lolli

Copyright ( 92022 He-Hua Wang et al. This is an open access article distributed under the Creative Commons Attribution License, which permits unrestricted use, distribution, and reproduction in any medium, provided the original work is properly cited.

To deal with emergencies in the development of large passenger aircraft, the optimization of supply chain resilience is studied. First, based on the "main manufacturer-supplier" model adopted by the synergistic development supply chain of large passenger aircraft, a resilience analysis framework is established from the perspective of the main manufacturer and supplier, based on which a bilateral grey quality function deployment resilience measurement model is proposed. Second, a single-perspective resilience optimization model of the main manufacturer and supplier under cost constraints is constructed. Then, an overall resilience optimization model of the supply chain considering the synergistic effect and cooperation uncertainty is presented. Finally, the development of a large airliner's fuselage is taken as an example to illustrate the feasibility and validity of the proposed model. The results show that (1) the synergy between the main manufacturers and suppliers can not only improve resilience of the whole supply chain, but also reduce their own competitiveness and resilience, respectively; (2) a benign cooperative relationship can effectively improve the overall resilience; on the contrary, it can reduce the overall elasticity; (3) the cost of supply chain has a great impact on the resilience of the main manufacturers and suppliers, respectively.

\section{Introduction}

A large aircraft consists of millions of parts, which usually take years to decades to develop and manufacture, and the civil aircraft parts used need to be supplied by a number of suppliers around the world. Additionally, the large number of suppliers and complex distribution areas make the large aircraft supply chain face various threats; for example, Boeing 737 and 787 and Airbus A350 have successively experienced problems with delayed delivery of orders because of poor supply chain management. Therefore, it is not difficult to find that even mature civil aircraft manufacturers have difficulty in avoiding the impact of supply chain emergencies. Actually, under the current social and economic conditions, the real competition is not between enterprises but that of the supply chain $[1,2]$. Nowadays, the outsourcing, internationalization, and complexity of the aviation supply chain make aircraft manufacturers depend on one another in structure [3]; thus most of the delay and quality problems can also be traced back to the supply chain management and cooperation problems [4]. Given the long development cycle, high technical level, and high efficiency and quality requirements of large aircraft, the supply chain will face various kinds of sudden interruption problems. The high incidence of these problems will lead to rising levels of risk $[5,6]$, whereas resilience ensures that the supply chain can recover quickly and economically from the interruption [7]. Therefore, improvement of the overall control ability and resilience of the large aircraft supply chain is a subject of practical significance.

In recent years, scholars have paid increasing attention to the resilience of the supply chain. Supply chain resilience indicates that all affected enterprises in the supply chain can quickly recover from destructive events and return to a 
normal state or better operation state [8-10]. At present, research in this field mainly focuses on the definition $[8,11,12]$, measurement [13-16], and method of shaping and optimization of supply chain resilience [17-20]. For the measurement of supply chain resilience, $\mathrm{Xu}$ et al. [13] developed a quantitative model for analyzing and predicting supply chain resilience based on the structural evolution of stochastic supply interruption. Focusing on the reliability evaluation of a multistage supply chain with multiple suppliers, Lin et al. [14] proposed a network reliability evaluation method based on the minimum path. Anoop et al. [16] built a multilevel evaluation platform for supply chain elasticity by using the expert scoring method and generalized fuzzy trigonometric function. They also measured the level of supply chain resilience from several modules, such as supply chain process reengineering, collaboration, culture, and flexibility. In terms of supply chain resilience optimization, Sang and Jin [17] proposed that enhancing organizational flexibility can effectively improve supply chain resilience and reduce the negative impact caused by interruptions. Quan et al. [18] used system dynamics to conduct dynamic simulation modeling of three-tier supply chain disruption in the cheese industry. They believed that cooperation among members would help the supply chain to recover rapidly and reduce the impact of disruption. Peter and Yuri [19] presented that lean production, six sigma management, improvement in the supply chain flexibility, and enhancement in corporate culture construction can improve enterprise resilience. Wang [20] pointed out that threat identification, redundant management, flexible construction, supply chain reconstruction, and security measures such as strengthening cooperation are effective means of optimizing enterprise resilience.

The quality function deployment (QFD) technique was proposed in Japan during the 1970s [21-23]. This technique is a systematic process for translating customer needs into engineering characteristics of a product or service to ensure a quality level that meets the desires of the customer throughout each stage of production [24]. The core tool of QFD is the house of quality (HOQ), which can analyze the relationship among different parts [25]. With the continuous improvement of production technology and method, QFD is applied in various industries, such as manufacturing, transportation, platform design, construction, education, and service [26-28]. It is also widely used in the field of supply chain [29-33]. The large aircraft supply chain adopts the organization mode of "main manufacturer-supplier." The main manufacturer and suppliers have their own resilience evaluation indicators and measures. HOQ is used to explore the relationship between evaluation indicators and measures and the correlation between resilience measures. Furthermore, HOQ is used to obtain resilience values of the main manufacturer, suppliers, and whole supply chain.

Some studies $[34,35]$ have examined how to measure and improve the supply chain management level and resilience of large passenger aircraft. Most of the reported literature measured and optimized the resilience of the whole supply chain. However, the existing research methods are not reasonable because of the selfish behavior of the main manufacturer and supplier and the existence of synergy. Considering the influence of the behaviors of the main manufacturer and suppliers on the resilience of the whole supply chain, the present paper constructs a bilateral grey QFD model to measure the resilience of the supply chain from the perspectives of the main manufacturer and suppliers. In view of the limitations and subjectivity of the evaluator's knowledge, the true and objective reflection of the objects being evaluated is only a value of the evaluation intervals given by the evaluators. In this paper, we build a bilateral grey QFD model to measure the supply chain resilience: a resilience optimization model of the main manufacturer and suppliers without considering the synergy effect under the cost constraint and a resilience optimization model of the whole supply chain considering the synergy effect and the uncertainty of cooperation. The supply chain resilience is optimized through the collaborative implementation of measures of the two roles in the supply chain.

The remainder of this paper is organized as follows. Based on the organizational model of the supply chain of large aircraft and considering the synergy between the main manufacturer and suppliers, Section 2 constructs a bilateral QFD supply chain resilience measurement model. According to the output of the measurement model, Section 3 constructs three resilience optimization models, namely, the cost-constrained resilience optimization model from the perspective of the main manufacturer that does not consider the synergy; the cost-constrained resilience optimization model from the perspective of suppliers that does not consider the synergy; and the supply chain overall resilience optimization model that considers the cooperation uncertainty and synergy. Taking the domestic large aircraft fuselage supply chain as an example, Section 4 verifies the feasibility and effectiveness of the models proposed by this paper. Section 5 summarizes the whole paper, analyzing the contribution, deficiency, and future research direction of the paper.

\section{Bilateral Grey Quality Function Deployment Measurement Model}

The supply chain of China's self-developed large aircraft adopts the "main manufacturer-supplier" mode. Considering the lack of core technology, the main manufacturer has no strong control over numerous suppliers, thereby making the existing supply chain resilience measurement methods not very suitable. From the perspective of the main manufacturer and supplier, considering the relationship between the two, a bilateral QFD framework is established to measure the overall resilience of the supply chain.

The measurement model consists of two HOQs, that is, the measurement HOQ from the perspective of the main manufacturer and the measurement HOQ from the perspective of the supplier, including the cooperation matrix between the two sides. The HOQ is composed of six parts, namely, the left wall, right wall, ceiling, roof, room, and basement, as shown in Figure 1. 


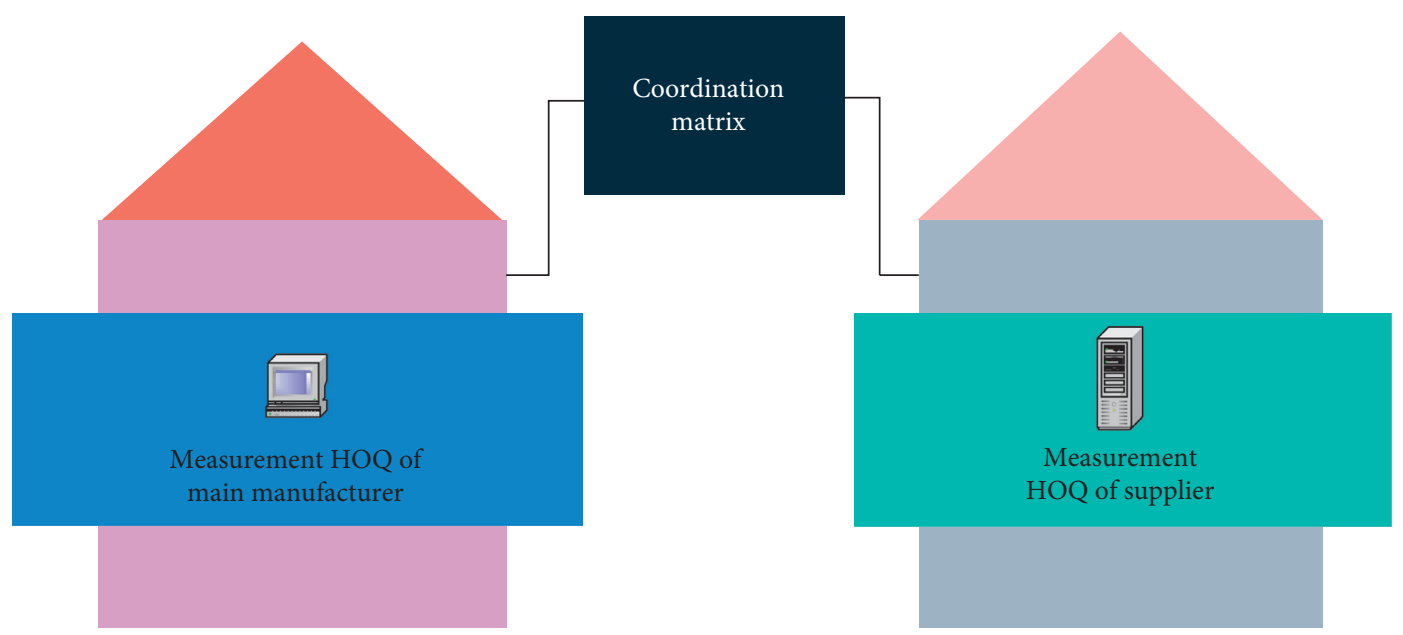

FIGURE 1: Bilateral QFD model for the supply chain resilience measurement.

2.1. Left Wall of the Measurement HOQ. The left wall represents the elastic evaluation indicator matrix; $C R^{h}(h=1,2)$ represent the main manufacturer and the supplier, respectively, and the weight vector of the evaluation indicator $W^{h}$. $W^{h}$ is obtained through the grey Delphi method. The evaluation value of the subject is expressed by the interval grey number with the domain $[0,1][36]$. Here the grey value and kernel are used to express the grey number evaluation value according to [37], and the final weight vector can be obtained through (1)-(3).

$$
\begin{aligned}
& \otimes\left(w_{i}^{h k}\right) \in\left[\underline{w_{i}^{h k}}, \overline{w_{i}^{h k}}\right], \\
&\left(h=1,2 ; k=1,2, \ldots q^{h} ; i=1,2, \ldots, m^{h}\right), \\
& \otimes\left(w_{i}^{h}\right)=\frac{\sum_{k=1}^{q^{h}} \otimes\left(w_{i}^{h k}\right)}{q^{h}} \in\left[\frac{\sum_{k=1}^{q^{h}}\left(w_{i}^{h k}\right)}{q^{h}}, \frac{\sum_{k=1}^{q^{h}}\left(w_{i}^{h k}\right)}{q^{h}}\right] \\
&=\left[\frac{\left.w_{i}^{h}, \overline{w_{i}^{h}}\right],}{\left(h=1,2 ; k=1,2, \ldots, q^{h} ; i=1, \ldots, m^{h}\right),}\right. \\
& w_{i}^{h}=\widehat{\otimes}\left(w_{i}^{h}\right)\left(g^{0}\left(w_{i}^{h}\right)\right)
\end{aligned}
$$

where $\otimes\left(w_{i}^{h k}\right)$ denotes the evaluation value of evaluator $k$ for resilience indicator $\mathrm{cr}_{i}^{h}$; $a, \bar{a}$ indicate the upper and lower limits of the interval, respectively, and if $\underline{a}$ is equal to $\bar{a}$, the grey number $\otimes \in[a, \bar{a}]$ turns into a white number where the value is $\underline{a}$ or $\bar{a} ; q^{h}$ denotes the number of the evaluator; $m^{h}$ represents the number of resilience evaluation indicator; and $w_{i}^{h}$ is the weight value of $c r_{i}^{h}$.

2.2. Right Wall of the Measurement HOQ. The right wall indicates the competitive evaluation matrix, which is composed of interval grey numbers. The element values of the matrix are normalized by (4)-(9).

$$
\begin{aligned}
& \otimes\left(c a_{i}^{h l}\right) \in\left[\underline{c a_{i}^{h}, \overline{c a_{i}^{h}}}\right] \\
& \left(h=1,2 ; i=1,2, \ldots ., m^{h}\right) \text {, } \\
& \otimes\left(c a^{h l}\right)=\sum_{i=1}^{m^{h}} \otimes\left(c a_{i}^{h l}\right) \in\left[\sum_{i=1}^{m^{h}} c a_{i}^{h l}, \sum_{i=1}^{m^{h}} \overline{c a_{i}^{h l}}\right] \\
& =\left[\underline{c a^{h l}}, \overline{c a^{h l}}\right] \text {, } \\
& \left(h=1,2 ; i=1,2, \ldots, m^{h} ; l=1,2, \ldots, p^{h}\right), \\
& c a^{h l}=\widehat{\otimes}\left(c a^{h l}\right)\left(g^{0}\left(c a^{h l}\right)\right) \\
& \frac{c o a^{h l}=\frac{c a^{h l}-c a^{h l-}}{d},}{c o a^{h l}}=\frac{\overline{c a^{h l}}-c a^{h l-}}{d}, \\
& \left(h=1,2 ; l=1,2, \ldots, p^{h}\right), \\
& \otimes\left(\operatorname{coa}^{h l}\right) \in\left[\operatorname{coa}^{h l}, \overline{\operatorname{coa}^{h l}}\right],\left(h=1,2 ; l=1,2, \ldots, p^{h}\right), \\
& \lambda_{l}^{h}=\frac{\widehat{\otimes}\left(c o a^{h l}\right)_{\left(g^{0}\left(c o a^{h l}\right)\right)}}{\sum_{l=1}^{p^{h}} \widehat{\otimes}\left(c o a^{h l}\right)_{\left(g^{0}\left(c o a^{h l}\right)\right)}},\left(h=1,2 ; l=1,2, \ldots, p^{h}\right),
\end{aligned}
$$

where $\otimes\left(c a_{i}^{h l}\right)$ means the evaluation value of the competitor $l^{h}$ under the evaluation indicator $c r_{i}^{h}$; $P^{h}$ represents the number of competitors; $c a^{h l}$ is the competitive evaluation value of the competitor $l^{h} ; c a^{h l-}=\min c a^{h l}$ and $d=\max \overline{c a^{h l}}-\min c a^{h l}$ represent the range of the competitive evaluation values, $d$ is the domain of the evaluation value, and $\otimes\left(\operatorname{coa}^{h l}\right)$ denotes the normalized competitive evaluation value. According to [36], the normalized 
evaluation values are normalized grey number, and the grey level is the same as the original interval grey number. $\widehat{\otimes}\left(\operatorname{coa}^{h l}\right)$ represents the kernel of the competitive evaluation value, while $\lambda_{l}^{h}$ demonstrates the competition of the competitors.
2.3. Ceiling and Roof of the Measurement HOQ. The ceiling is the matrix of resilience measures $E C^{h},(h=1,2)$, indicating the resilience measures taken by the main manufacturer and suppliers, which are obtained from the enterprise research.

The roof is the correlation matrix of resilience measures, which is composed of interval grey numbers with domain $[0$, $1]$.

$$
\begin{aligned}
& \otimes\left(c_{i j}^{h k}\right) \in\left[\underline{c_{i j}^{h k}}, \overline{c_{i j}^{h k}}\right], \\
&\left(h=1,2 ; k=1,2, . ., q^{h} ; i=1,2, \ldots, n^{h} ; j \neq i, j=1,2, . ., n^{h}\right), \\
& \otimes\left(c_{i j}^{h}\right)= \frac{\sum_{k=1}^{q^{h}} \otimes\left(c_{i j}^{h k}\right)}{q^{h}} \in\left[\frac{\sum_{k=1}^{q^{h}} c_{i j}^{h k}}{q^{h}}, \frac{\sum_{k=1}^{q^{h}} c_{i j}^{h k}}{q^{h}}\right]=\left[\underline{c_{i j}^{h}}, \overline{c_{i j}^{h}}\right], \\
&\left(h=1,2 ; i=1,2, \ldots, n^{h} ; j \neq i, j=1,2, . ., n^{h}\right), \\
& c_{i j}^{h}=\widehat{\otimes}\left(c_{i j}^{h}\right)_{\left(g^{o}\left(c_{i j}^{h}\right)\right)}
\end{aligned}
$$

where $\otimes\left(c_{i j}^{h k}\right)$ indicates the evaluation value of evaluator $k$ for the correlation between resilience measures $e c_{i}^{h}$ and $e c_{j}^{h} ; n^{h}$ represents the number of resilience measures; and $c_{i j}^{h}$ denotes the final evaluation value of the correlation between $e c_{i}^{h}$ and $e c_{j}^{h}$.
2.4. Room of the Measurement HOQ. The room is the relation matrix $R^{h},(h=1,2)$ between the resilience evaluation indicator and resilience measures, composed of interval grey numbers with the domain $[0,1]$.

$$
\begin{aligned}
\otimes\left(r_{i j}^{h k}\right) \in\left[\underline{r_{i j}^{h k}}, \overline{r_{i j}^{h k}}\right], \\
\left(h=1,2 ; k=1,2, \ldots, q^{h} ; i=1,2, \ldots, m^{h} ; j=1,2, \ldots, n^{h}\right), \\
\otimes\left(r_{i j}^{h}\right)=\frac{\sum_{k=1}^{q^{h}} \otimes\left(r_{i j}^{h k}\right)}{q^{h}} \in\left[\frac{\sum_{k=1}^{q^{h}} r_{i j}^{h k}}{q^{h}}, \frac{\sum_{k=1}^{q^{h}} \overline{r_{i j}^{h k}}}{q^{h}}\right]=\left[\underline{r_{i j}^{h}}, \overline{r_{i j}^{h}}\right], \\
\left(h=1,2 ; i=1,2, \ldots, m^{h} ; j=1,2, \ldots, n^{h}\right), \\
r_{i j}^{h}=\widehat{\otimes}\left(r_{i j}^{h}\right)\left(g^{0}\left(r_{i j}^{h}\right)\right)
\end{aligned}
$$

where $\otimes\left(r_{i j}^{h k}\right)$ indicates the evaluation value given by the evaluators for the relationship between the indicator $c r_{i}^{h}$ and resilience measure $e c_{j}^{h} ; q^{h}$ represents the number of the evaluator; $n^{h}$ indicates the number of the resilience measure; and $r_{i j}^{h}$ is the final relationship between the indicator $c r_{i}^{h}$ and measure $e c_{j}^{h}$.

2.5. Basement of the Measurement HOQ. The basement indicates the output of the measurement HOQ including the absolute importance matrix of the resilience measures $A E C^{h},(h=1,2)$, relative importance matrix $R E C^{h},(h=1,2)$, and implementation cost matrix
$\operatorname{COT}^{h},(h=1,2)$. Based on the relation matrix $R^{h}$ and correlation matrix $C^{h}$, relative importance and absolute importance can be obtained.

$$
\begin{gathered}
R_{\text {new }}^{h}=R^{h} \times C^{h}, \\
(h=1,2), \\
\otimes\left(\operatorname{aec}_{j}^{h}\right)=\sum_{i=1}^{m^{h}}\left[\otimes\left(w_{i}^{h}\right) \times r_{\text {newij }}^{h}\right], \\
\left(h=1,2 ; j=1,2, \ldots, n^{h}\right),
\end{gathered}
$$




$$
\begin{gathered}
\operatorname{aec}_{j}^{h}=\widehat{\otimes}\left(a e c_{j}^{h}\right)\left(g^{0}\left(\operatorname{aec}_{j}^{h}\right)\right), \\
\otimes\left(\operatorname{rec}_{j}^{h}\right)=\frac{\otimes\left(\operatorname{aec} c_{j}^{h}\right)}{\sum_{j=1}^{n^{h}} \otimes\left(a e c_{j}^{h}\right)}, \\
\left(h=1,2 ; j=1,2, \ldots, h^{h}\right), \\
\operatorname{rec}_{j}^{h}=\widehat{\otimes}\left(\operatorname{rec}_{j}^{h}\right)\left(g^{0}\left(\operatorname{rec}_{j}^{h}\right)\right),
\end{gathered}
$$

where $R_{\text {new }}^{h}$ indicates the verified relation matrix, and $r_{\text {newij }}^{h}$ represents the element of the matrix $R_{\text {new; }}^{h}$; aec ${ }_{j}^{h}$ means the absolute importance of $\mathrm{ec}_{j}^{h}$; and $\operatorname{rec}_{j}^{h}$ means the relative importance of $\mathrm{ec}_{j}^{h}$.

2.6. Cooperation of the Measurement HOQ. The cooperation matrix $A$ demonstrates the relationship between the measures adopted by the main manufacturer and suppliers, and the element of the matrix $a_{i j},\left(i=1,2, \ldots, n^{1} ; j=1,2, \ldots, n^{2}\right)$ can be defined by (19). The resilience $K^{h},(h=1,2)$ of the main manufacturer and suppliers can be obtained by (20).

$$
\begin{array}{r}
a_{i j} \begin{cases}1, & \text { when } \mathrm{ec}_{i}^{1}, \mathrm{ec}_{j}^{2} \text { support each other, } \\
0, & \text { when } \mathrm{ec}_{i}^{1} \mathrm{ec}_{j}^{2} \text { have no relationship, } \\
-1, & \text { when } \mathrm{ec}_{i}^{1}, \mathrm{ec}_{j}^{2} \text { offset each other, }\end{cases} \\
K^{h}=\widehat{\otimes}\left(K^{h}\right)_{\left(g^{\circ}\left(K^{1}\right)\right)}=\sum_{j=1}^{h^{h}} \widehat{\otimes}\left(\operatorname{aec}_{j}^{h}\right), \\
\left(h=1,2 ; x j=1,2, \ldots, n^{h}\right),
\end{array}
$$

where $K^{h}$ denotes the resilience of the main manufacturer (when $h=1$ ) and suppliers (when $h=2$ ).

According to the hypothesis of the model and [38], the resilience of the whole supply chain can be calculated by

$$
K=\otimes(K)=\frac{1}{\widehat{\otimes}\left(K^{1}\right)_{\left(g^{o}\left(K^{1}\right)\right)}}+\frac{1}{N \widehat{\otimes}\left(K^{2}\right)_{\left(g^{o}\left(K^{2}\right)\right)}}=\left(\frac{1}{\widehat{\otimes}\left(K^{1}\right)}+\frac{1}{N \widehat{\otimes}\left(K^{2}\right)}\right)_{\left(g^{o}\left(K^{1}\right) \vee g^{o}\left(K^{2}\right)\right)},
$$

where $\widehat{\otimes}\left(K^{1}\right)_{\left(g^{o} K^{1}\right)}$ denotes the resilience of the main manufacturer; $\frac{\partial}{\otimes}\left(K^{2}\right)_{\left(g^{\circ} K^{2}\right)}$ represents the resilience of suppliers; $N$ demonstrates the number of suppliers; and $g^{0}\left(K^{1}\right) \vee g^{0}\left(K^{2}\right)$ represents the grey level of the new grey number, which is larger than the original grey numbers according to the axiom of no reduction of grey level [36].

\section{Resilience Optimization Model}

Based on the correlation between resilience measures from the two sides and considering the cooperation uncertainty, a resilience optimization model is built by synergistically implementing resilience measures to enhance the supply chain resilience. For the simplicity of calculations and readability of symbolic representations, the resilience measurement and optimization model are constructed based on the following assumptions: the resilience standards of all suppliers are consistent; the implementation cost for each vendor for the same resilience measures is the same; and the supply chain adopts the connection mode of series connection between main manufacturers and suppliers and a parallel connection between suppliers.

The resilience values of the main manufacturer and suppliers are obtained from the measurement model. Through the reasonable selection of their own measures, the resilience values within the acceptable range can be obtained, thereby satisfying the cost limit. Therefore, the following resilience optimization models of the main manufacturer (M-1) and suppliers (M-2) without considering the synergy effect are constructed. Both models have two objectives as follows: to maximize their own resilience values and competitiveness.

M-1: resilience optimization model from the perspective of the main manufacturer without considering the synergy effect.

$$
\begin{aligned}
& \max f_{1}^{1}(X)=\widehat{\otimes}\left(K^{1}\right)=\sum_{i=1}^{n^{1}} \widehat{\otimes}\left(\operatorname{aec}_{i}^{1} x\right)_{i}^{1} \\
& \max f_{2}^{1}(X)=\sum_{l=1}^{p^{1}} \lambda_{l}^{1}\left(\widehat{\otimes}\left(K^{1}\right)-\widehat{\otimes}\left(\operatorname{coa}^{1 l}\right)\right) \text { s.t. }\left\{\begin{array}{l}
x(1-x)=0 \\
\frac{\sum_{i=1}^{n^{1}} \widehat{\otimes}\left(\operatorname{aec}_{i}^{1}\right)-K^{1 *}}{K^{1 *}} \geq-\beta^{1} \sum_{i=1}^{n^{1}} x_{i}^{1} \geq 1 \frac{B^{1}-\sum_{i=1}^{n^{1}} x_{i}^{1} \cot _{i}^{1}}{\alpha^{1}} \geq B^{1},
\end{array}\right.
\end{aligned}
$$




$$
\begin{aligned}
& x_{i}^{1}=\left\{\begin{array}{ll}
1, & \text { when measure } e c_{i}^{1} \text { continues to be implemented } \\
0, & \text { when measure } e c_{i}^{1} \text { stops being implemented }
\end{array},\right. \\
& x_{i}^{2}=\left\{\begin{array}{ll}
1, & \text { when measure } e c_{i}^{2} \text { continues to be implemented } \\
0, & \text { when measure } e c_{j}^{2} \text { stops being implemented }
\end{array},\right.
\end{aligned}
$$

where $x_{i}^{1}$ is the decision variable, defined by $(22) ; K^{1 *}$ denotes the lower limit of the resilience of the main manufacturer; $-\beta^{1}, \beta^{1} \in[0,1]$ indicates the acceptable negative relative deviation between the actual resilience value of the main manufacturer and lower limit; $B^{1}$ denotes that the cost budget can be used for resilience optimization; and $\alpha^{1}$ reflects the relative cost saving of the main manufacturer. The meanings of the constraints in the model are as follows: the range of decision variable; the negative relative deviation of the main manufacturer's optimized resilience to the lower limit is within a predetermined acceptable range; at least one of its own resilience measures is implemented; and the relative savings of the main manufacturer's resilience optimization cost are not lower than the preset value.

M-2: resilience optimization model from the perspective of suppliers without considering the synergy effect.

$$
\begin{aligned}
& \max f_{2}^{2}(X)=\widehat{\otimes}\left(K^{2}\right)=\sum_{i=1}^{n^{2}} \widehat{\otimes}\left(\operatorname{aec}_{i}^{2} x\right)_{i}^{2} \\
& \max f_{2}^{2}(X)=\sum_{l=1}^{p^{2}} \lambda_{l}^{2}\left(\widehat{\otimes}\left(K^{2}\right)-\widehat{\otimes}\left(\operatorname{coa}^{2 l}\right)\right) \\
& \text { s.t. }\left\{\begin{array}{l}
\frac{x(1-x)=0 ; \sum_{i=j}^{n^{2}} x_{j}^{2} \geq 1}{\sum_{j=1}^{n^{2}} \widehat{\otimes}\left(\operatorname{aec}_{j}^{2}\right)-K^{2 *}} \\
K^{2 *} \\
\frac{B^{2}-\sum_{j=1}^{n^{2}} x_{j}^{2} \cot _{j}^{2}}{\alpha^{2}} \geq B^{2}
\end{array}\right.
\end{aligned}
$$

where $x_{j}^{2}$ is the decision variable, which is defined by (22); $K^{2 *}$ denotes the lower limit of the resilience of suppliers; $-\beta^{2}, \beta^{2} \in[0,1]$ indicates the acceptable negative relative deviation between the actual resilience value of suppliers and the lower limit; $B^{2}$ denotes that the cost budget can be used for resilience optimization; and $\alpha^{2}$ reflects the relative cost saving of suppliers. The meanings of the constraints in the model are as follows: the range of decision variable; the negative relative deviation of suppliers' optimized resilience to the lower limit is within a predetermined acceptable range; at least one of its own resilience measures is implemented; and the relative savings of suppliers' resilience optimization cost are not lower than the preset value.

M-3: resilience optimization model from the perspectives of the main manufacturer and suppliers considering the synergy effect. The incomplete cooperation between the two partners, that is, opportunistic behaviors, will hinder the improvement of supply chain resilience. A resilience optimization model considering the synergy effect and cooperation uncertainty is constructed to enhance the supply chain resilience through the optimal implementation of the resilience measures of both parties. The two objective functions are to maximize the resilience of the supply chain and competitiveness of each role. Given that the meaning of kernel of grey number is similar to mean or expectation, only the maximum value of kernel of resilience expressed by grey number is obtained here, and the final model definition is as follows (M-3-1):

$$
\begin{aligned}
& \max f_{1}(X)=\widehat{\otimes}(K)=\frac{1}{\widehat{\otimes}\left(K^{1}\right)}+\frac{1}{N \widehat{\otimes}\left(K^{2}\right)}+\varepsilon N\left[\left(\widehat{\otimes}\left(K^{1}\right) \widehat{\otimes}\left(K^{2}\right)\right],\right. \\
& \max f_{2}^{h}(X)=\sum_{l=1}^{p^{h}} \lambda_{l}^{h}\left(\widehat{\otimes}\left(K^{h}\right)-\widehat{\otimes}\left(\operatorname{coa}^{h l}\right)\right),(h=1,2),
\end{aligned}
$$




$$
\text { s.t. }\left\{\begin{array}{l}
\frac{\widehat{\otimes}\left(K^{1}\right)-K^{1^{*}}}{K^{1^{*}} \geq-\beta^{1},} \\
\frac{\widehat{\otimes}\left(K^{2}\right)-K^{2^{*}}}{K^{2 *}} \geq-\beta^{2}, \\
\text { s.t. }\left\{\begin{array}{l}
\sum_{i=1}^{n^{1}} x_{i}^{1} \geq 1, \\
\frac{\sum_{j=1}^{n^{2}} x_{j}^{2} \geq 1,}{B^{1}-\sum_{i=1}^{n^{1}} x_{i}^{1} \cot _{i}^{1}} \geq B^{1}, \\
\alpha^{1} \\
\operatorname{COT}^{1} \sum_{i=1}^{n^{1}} x_{i}^{1} \cot _{i}^{1}+\sum_{j=1}^{n^{2}} x_{i}^{2} \cot _{i}^{2} \\
\frac{B^{2}-\sum_{j=1}^{n^{2}} x_{i}^{2} \cot _{i}^{2}}{\alpha^{2}} \geq B^{2}, \\
\text { if } a_{i j}=1, x_{i}^{1} x_{j}^{2}=1 ;
\end{array}\right.
\end{array}\right.
$$

where $x_{i}^{1}, x_{j}^{2}$ are decision variables, defined by equation (23); $\varepsilon \in[-1,1]$ is random, indicating the cooperation uncertainty. When $\varepsilon<0$, divergences exist between the main manufacturer and suppliers. When $\varepsilon>0$, it indicates a benign partnership between two supply chain roles; $-\beta^{h}, \beta^{h} \in[0,1]$ indicate the acceptable negative relative deviations between the actual resilience values of the two supply chain roles and their lower limits; $B^{h},(h=1,2)$ represent the cost budget that can be used for resilience optimization; $\alpha^{h},(h=1,2)$ reflects the relative cost savings of the main manufacturer and suppliers; COT indicates the overall cost budget of the supply chain; $\alpha$ reflects the relative amount of total cost savings; and $a_{i j},\left(i=1,2, \ldots, n^{1} ; j=\right.$ $\left.1,2, \ldots, n^{2}\right)$ indicates the element of the cooperation matrix A.

Notably, according to equation (22) and (23), when $x_{i}^{1}=0, \widehat{\otimes}\left(a e c_{i}^{1}\right)=0$. Similarly, when $x_{j}^{2}=0, \widehat{\otimes}\left(a e c_{j}^{2}\right)=0$, the model (M-3-1) can be written as follows:

$$
\begin{aligned}
& \max f_{1}(X)=\widehat{\otimes}(K)=\frac{1}{\widehat{\otimes}\left(\sum_{i=1}^{n^{1}} \operatorname{aec}_{i}^{1} x_{i}^{1}\right)}+\frac{1}{N \widehat{\otimes}\left(\sum_{j=1}^{n^{2}} \operatorname{aec}{ }_{j}^{2} x_{j}^{2}\right)}-\varepsilon N\left[\left(\widehat{\otimes}\left(\sum_{i=1}^{n^{1}} \operatorname{aec} c_{i}^{1} x_{i}^{1}\right) \widehat{\otimes}\left(\sum_{j=1}^{n^{2}} \operatorname{aec}_{j}^{2} x_{j}^{2}\right)\right]\right. \\
& \max f_{2}^{1}(X)=\sum_{l=1}^{p^{1}} \lambda_{l}^{1}\left(\widehat{\otimes}\left(K^{1}\right)-\widehat{\otimes}\left(\operatorname{coa}^{1 l}\right)\right) \\
& \max f_{2}^{2}(X)=\sum_{l=1}^{p^{2}} \lambda_{l}^{2}\left(\widehat{\otimes}\left(K^{2}\right)-\widehat{\otimes}\left(\operatorname{coa}^{2 l}\right)\right),
\end{aligned}
$$




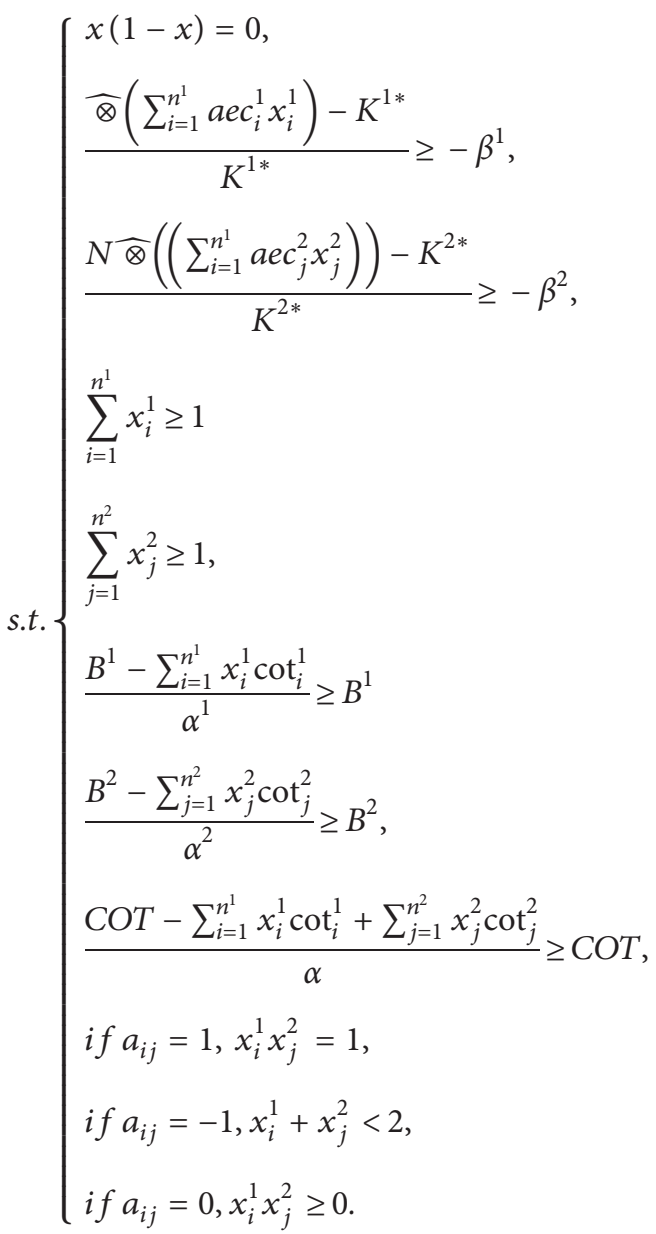

The meanings of constraints in the model are as follows: the definition of the decision variables; the degree of resilience of negative deviations after optimization between the main manufacturer and suppliers with respect to their respective lower limit should be within the acceptable range set in advance; two kinds of supply chain roles should implement at least one of their own resilience measures; the relative savings of resilience optimization costs and total cost between the main manufacturer and suppliers should not be less than the preset values; according to the cooperation matrix, when the resilience measures of the main manufacturer and suppliers promote each other, the corresponding measures shall be implemented continuously; when the measures of the main manufacturer and suppliers resist each other, the corresponding measures of the two cannot be implemented at the same time; when no relationship exists between the measures of the main manufacturer and suppliers, the implementation of the two measures has no requirements.

The geometric weighting method is used to reconstruct the above multiobjective programming. In other words, the new objective function is $g(X)=\max \eta_{i} f_{i}(X)$, where $\eta_{i}>0$, $\sum_{i=1}^{n} \eta_{i}=n$ means the preference of the decision makers for the original objective functions $f_{i}(X)$, and $n$ means the number of the original objective functions. According to
[39], the solutions of the reconstructed model are all effective solutions of the original model.

\section{Case Study}

4.1. Background Description. The COMAC is the main manufacturer of domestic large aircraft, which gathers 16 material suppliers including Baosteel and 54 standard parts suppliers. The fuselage suppliers include Hongdu, Avic Chengdu Aircraft Industrial Co. Ltd., Avic Xi'an Aircraft Industry Company Ltd., and CASICHY. Among them, Chengdu Aircraft Industrial Co. Ltd. is responsible for the nose part, whereas Hongdu is responsible for the front fuselage and the middle and rear fuselage. Avic Xi'an Aircraft Industry Company Ltd. is responsible for the middle fuselage (including the wing box), and CASICHY is responsible for the rear section of the rear fuselage. As a supplier of the fuselage, Hongdu has spent six years completing the development of the front fuselage and middle and rear fuselage. Its development process includes many high technologies, including skin processing equipment, profile processing equipment, high-precision computer numerical control (CNC) processing equipment, $\mathrm{CNC}$ shot peening strengthening equipment, and digital assembly line. 
As the main supplier of the fuselage part of the large aircraft, Hongdu has a cooperative relationship with the main manufacturers and, simultaneously, a certain degree of competition in technology exists. To enhance the competitiveness of the manufacturing and assembly of the fuselage part and improve the resilience of the supply chain, the two roles should explore the collaborative method of resilience optimization.

\subsection{Determination of Evaluation Indicator and Measures.} The previous studies on the supply chain elasticity measurement and field research were sorted out. The main manufacturers and suppliers' respective resilience evaluation indicators (Table 1) and measures were determined, and the implementation cost of each measure was obtained through the simulation of real data (Table 2). The weight values of the indicators are calculated using (1)-(3).

Tables 1 and 2 show that, for the main manufacturer, a sound supplier management system is an important indicator to measure their own resilience. For suppliers, perfect supply capacity and reasonable inventory management level are important indicators to measure their own resilience. To improve their resilience, both sides have given enough investment in corresponding measures.

4.3. Bilateral QFD Measurement Model. By using the expert evaluation and (11)-(13), we can calculate the correlation matrix and relation matrix of the resilience measurement HOQ of the main manufacturer and suppliers, respectively; according to (14)-(18), we can calculate the basement part of the two roles' measurement HOQ; according to (4)-(9), we can calculate the competitive evaluation matrix and competitive weight of each competitor. Here, we choose A and $\mathrm{B}$ as competitors of the main manufacturer and C1, C2, and C3 as competitors of supplier Hongdu. Based on (19), we can obtain the cooperation matrix through expert evaluation. Figure 2 depicts the final bilateral QFD resilience measurement model.

According to the measurement model, we can obtain the resilience and competitiveness $K^{1}=2.98_{(0.4)}, \quad \sum_{l=1}^{2} \lambda_{l}^{1}$ $\left(\widehat{\otimes}\left(K^{1}\right)-\widehat{\otimes}\left(\operatorname{coa}^{1 l}\right)\right)=-1.21_{(0.4)}$ of the main manufacturer; the resilience and competitiveness of the supplier $K^{2}=3.41_{(0.4)}, \quad \sum_{l=1}^{3} \lambda_{l}^{2}\left(\widehat{\otimes}\left(K^{2}\right)-\widehat{\otimes}\left(c o a^{2 l}\right)\right)=0.41_{(0.4)}$; the resilience of the whole supply chain $K=0.63_{(0.4)}$. The above results show that the resilience of the main manufacturer of domestic large aircraft is weaker than that of their suppliers, and they are at a disadvantage compared with their competitors. Hongdu, the supplier, has certain competitiveness compared with its main competitors, but the capability is still relatively weak. Given the speculation and synergy between the main manufacturer and suppliers, the resilience of the whole supply chain is weaker than that of the main manufacturer and suppliers.

4.4. Resilience Optimization Model. According to the data obtained from the measurement model and the constant parameters in the model (Table 3), the resilience optimization model is constructed. First, the parameter sensitivity analysis is carried out for the models M-1 and M-2, and Figures 3 and 4 show the results. The influence of cooperation uncertainty on the objective functions of M-3 is discussed (Figure 5).

For model M-1, the sensitivity of cost and resilience constraint is analyzed (Figure 3). This paper found that when the constraint $\left(K^{1^{*}}\left(1-\beta^{1}\right)\right)$ is less than or equal to 2 , the values of objective functions do not change. However, when the constraint value is greater than 2 and if the cost constraint $\left(B^{1}\left(1-\alpha^{1}\right)\right)$ is kept unchanged, the optimal solution cannot be found. This finding indicates that the objective functions of the model are affected more by cost. Figure 3 shows that the change curve of the values of the two objective functions in the model with the change of cost constraints is the same, with an overall upward trend. However, when the value of the abscissa reaches 440, the values of the two objective functions will not change anymore, and all measures are put into practice at this time.

For model M-2, the sensitivity of cost and resilience constraint is analyzed. When the constraint $\left(K^{2^{*}}\left(1-\beta^{2}\right)\right)$ is less than or equal to 3 , the values of the objective functions do not change. However, when the constraint value is greater than 3 and if the cost constraint $\left(B^{2}\left(1-\alpha^{2}\right)\right)$ is kept unchanged, the optimal solution cannot be found. This result indicates that the objective functions of the model are more constrained by the cost. Figure 4 depicts that the trend of the two objective functions in the model changes with the cost constraint. Moreover, the trend is the same, with an overall upward trend. However, when the value of the abscissa reaches 310 , the values of the two objective functions tend to be stable, and all measures are put into operation at this time.

Figure 5 shows that when the coordinate uncertainty grows negatively, the objective function $f_{1}(X)$ also grows in a negative direction. When the cooperation uncertainty grows positively, the objective function also grows positively. This result indicates that the benign cooperation between the two parties can effectively improve the resilience of the entire supply chain. Moreover, when the absolute value of the cooperation uncertainty approaches 1 , the value curve is steeper. This finding indicates that when the value of cooperation uncertainty is more extreme, the impact on the objective function is greater.

Each objective function in the model is given weight. Models M-1, M-2, and M-3 are solved through the geometric weighting method, and Tables 4-6 show the solutions, respectively.

Compared with the results in Tables 4 and 5, Table 6 shows that the overall resilience of the entire supply chain is improved. However, considering the existence of synergies, the main manufacturer and supplier sacrifice a little of their own resilience. The decision makers are more satisfied with the solution of M-3 that is empowered as $1.5,0.85$, and 0.65 . The solution reflects that the resilience of the main manufacturer and the supplier is reduced by approximately $23 \%$ and $30 \%$, respectively, compared with when the synergistic effect is not considered. However, the resilience limit is still satisfied, which indicates that synergy is both cooperation and a certain degree of competition for both parties. 
TABLE 1: Resilience evaluation indicator.

\begin{tabular}{|c|c|c|c|c|}
\hline Role & Indicator & Connotation & $\begin{array}{c}\text { Grey } \\
\text { number }\end{array}$ & $\begin{array}{c}\text { Weight } \\
w_{i}^{h}\end{array}$ \\
\hline \multirow{6}{*}{$\begin{array}{l}\text { Main } \\
\text { manufacturer }\end{array}$} & $\begin{array}{c}c r_{1}^{1} \text { information } \\
\text { sharing }\end{array}$ & $\begin{array}{c}\text { Information sharing level with suppliers, smooth information } \\
\text { transmission, and timely handling of feedback }\end{array}$ & $0.65_{(0.3)}$ & $0.20_{(0.4)}$ \\
\hline & $\begin{array}{l}c r_{2}^{1} \text { financial } \\
\text { situation }\end{array}$ & $\begin{array}{c}\text { Diversification of capital, smoothness of circulation, and transparency of } \\
\text { capital consumption }\end{array}$ & $0.45_{(0.3)}$ & $0.14_{(0.4)}$ \\
\hline & $\begin{array}{l}c r_{3}^{1} \text { supplier } \\
\text { management }\end{array}$ & $\begin{array}{c}\text { The number and capacity of suppliers meet the requirements; appropriate } \\
\text { supplier resource pool and flexible supplier contracts }\end{array}$ & $0.75_{(0.3)}$ & $0.23_{(0.4)}$ \\
\hline & $\begin{array}{l}c r_{4}^{1} \text { modular } \\
\text { product design }\end{array}$ & $\begin{array}{c}\text { Modularization of product design, when there is a problem in a certain } \\
\text { part, it can be quickly focused on and solved }\end{array}$ & $0.35_{(0.3)}$ & $0.11_{(0.4)}$ \\
\hline & $c r_{5}^{1}$ cooperation & $\begin{array}{c}\text { Establishment of collaborative relationship; realizing the sharing of } \\
\text { interests and risks }\end{array}$ & $0.5_{(0.4)}$ & $0.16_{(0.4)}$ \\
\hline & $\begin{array}{l}c r_{6}^{1} \text { emergency } \\
\text { response }\end{array}$ & $\begin{array}{c}\text { Detect early warning information, crisis identification, and crisis handling } \\
\text { level }\end{array}$ & $0.5_{(0.2)}$ & $0.16_{(0.4)}$ \\
\hline \multirow{5}{*}{ Supplier } & $\begin{array}{c}c r_{1}^{2} \text { inventory } \\
\text { management }\end{array}$ & Proper inventory management mode and proper inventory quantity & $0.7_{(0.2)}$ & $0.23_{(0.4)}$ \\
\hline & $\begin{array}{l}c r_{2}^{2} \text { financial } \\
\text { situation }\end{array}$ & $\begin{array}{c}\text { Diversification of capital, smoothness of circulation, and transparency of } \\
\text { capital consumption }\end{array}$ & $0.45_{(0.3)}$ & $0.15_{(0.4)}$ \\
\hline & $\begin{array}{l}c r_{3}^{2} \text { emergency } \\
\text { response }\end{array}$ & $\begin{array}{l}\text { Detect early warning information, crisis identification, and crisis handling } \\
\text { level }\end{array}$ & $0.5_{(0.2)}$ & $0.17_{(0.4)}$ \\
\hline & $\begin{array}{l}\mathrm{cr}_{4}^{2} \text { information } \\
\text { sharing }\end{array}$ & $\begin{array}{l}\text { Information sharing level with main manufacturers and other suppliers, } \\
\text { smooth information transmission, and timely handling of feedback }\end{array}$ & $0.65_{(0.3)}$ & $0.22_{(0.4)}$ \\
\hline & $c r_{5}^{2}$ supply capability & Guarantee of lead time and capacity of production adjustment & $0.7_{(0.4)}$ & $0.23_{(0.4)}$ \\
\hline
\end{tabular}

TABLE 2: Resilience measure.

\begin{tabular}{|c|c|c|}
\hline Role & Resilience measure & $\begin{array}{l}\text { Cost (10 } \\
\text { thousand) }\end{array}$ \\
\hline \multirow{7}{*}{ Main manufacturer } & $e c_{1}^{1}$ Establishment of information sharing platform and information feedback mechanism & 90 \\
\hline & $e c_{2}^{1}$ Perfecting financial supervision mechanism and implementing financial transparency management & 40 \\
\hline & $e c_{3}^{1}$ Establishment and improvement of supplier supervision and evaluation system & 90 \\
\hline & $e c_{4}^{1}$ Continuous optimization of product design process & 35 \\
\hline & $e c_{5}^{1}$ Establishment and improvement of supplier resource pool & 50 \\
\hline & $e c_{6}^{1}$ Improvement of risk identification emergency system & 70 \\
\hline & $e c_{7}^{1}$ Flexible contract terms and strategic partnership with partners & 60 \\
\hline \multirow{5}{*}{ Suppliers } & $e c_{1}^{2}$ Collaborative implementation of multiple inventory management modes & 80 \\
\hline & $e c_{2}^{2}$ Perfecting financial supervision mechanism and implementing financial transparency management & 35 \\
\hline & $e c_{3}^{2}$ Establishment of information sharing mechanism & 70 \\
\hline & $e c_{4}^{2}$ Updating and improvement of production technology in time and iteratively & 60 \\
\hline & $e c_{5}^{2}$ Construction and improvement of risk identification and emergency system & 65 \\
\hline
\end{tabular}

The above analysis shows that the main manufacturer COMAC of domestic large aircraft is still in a disadvantaged position compared with its main competitors $\mathrm{A}$ and $\mathrm{B}$. The reason is that the mastery of core technology is not enough. COMAC needs to further accelerate technological progress, unite domestic and foreign suppliers to break technical barriers, and finally occupy a place in the field of civil aviation. Hongdu has certain competitive advantages among the same competitors. In the resilience optimization of the two roles, the establishment of the information sharing platform and establishment of the risk identification and emergency system are of great importance. For the main manufacturer, supplier management has relatively high importance. For the supplier, inventory management and improvement of supply capacity have a high degree of importance. Both parties should grasp the main measures and actively implement them to enhance resilience.

Cost has a great impact on their own resilience, and the main manufacturer and suppliers should make a reasonable cost plan according to their own conditions. The existence of synergy makes both parties become whole to some extent. A win-win cooperation can be achieved only by seeking the maximum cooperation based on ensuring their own interests. 


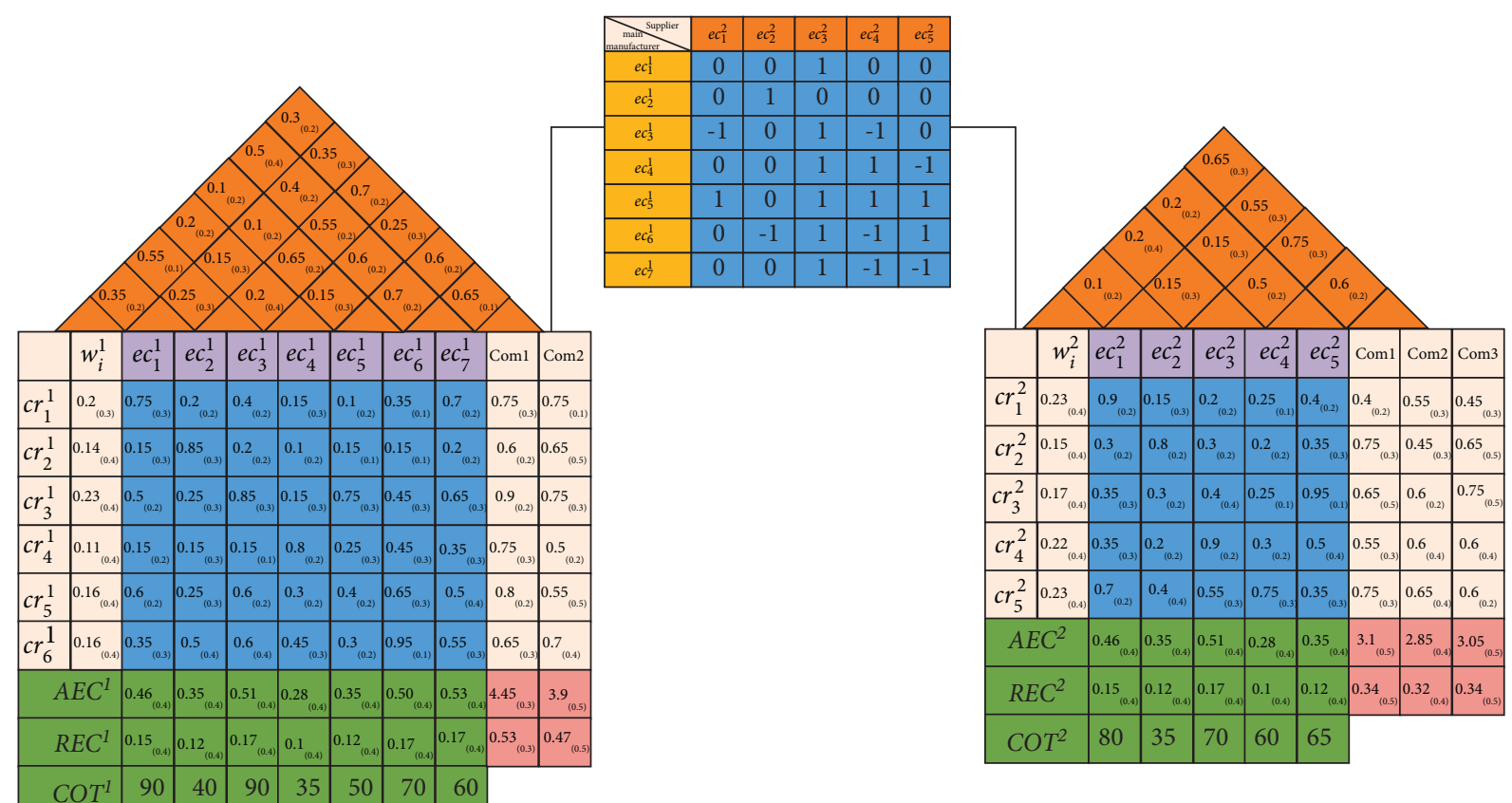

FIGURE 2: Fuselage supply chain resilience QFD measurement model.

TABLE 3: Constant parameter setting.

\begin{tabular}{|c|c|c|c|c|c|c|}
\hline Role & $\begin{array}{l}\text { Lower limit } \\
\qquad \begin{array}{c}K^{h *} \\
(h=1,2)\end{array}\end{array}$ & $\begin{array}{c}\text { Negative relative deviation of } \\
\text { resilience } \\
-\beta^{h}\end{array}$ & $\begin{array}{c}\text { Cost } \\
B^{h} \\
(h=1,2)\end{array}$ & $\begin{array}{c}\text { Relative cost } \\
\text { saving } \\
\alpha^{h}\end{array}$ & $\begin{array}{l}\text { Total } \\
\text { cost } \\
\text { COT }\end{array}$ & $\begin{array}{l}\text { Negative } \\
\text { relative } \\
\text { total cost saving }\end{array}$ \\
\hline $\begin{array}{l}\text { Main } \\
\text { manufacturer }\end{array}$ & 2 & -0.1 & 400 & 0.12 & \multirow[t]{2}{*}{680} & \multirow[t]{2}{*}{0.12} \\
\hline Supplier & 3 & -0.1 & 300 & 0.15 & & \\
\hline
\end{tabular}

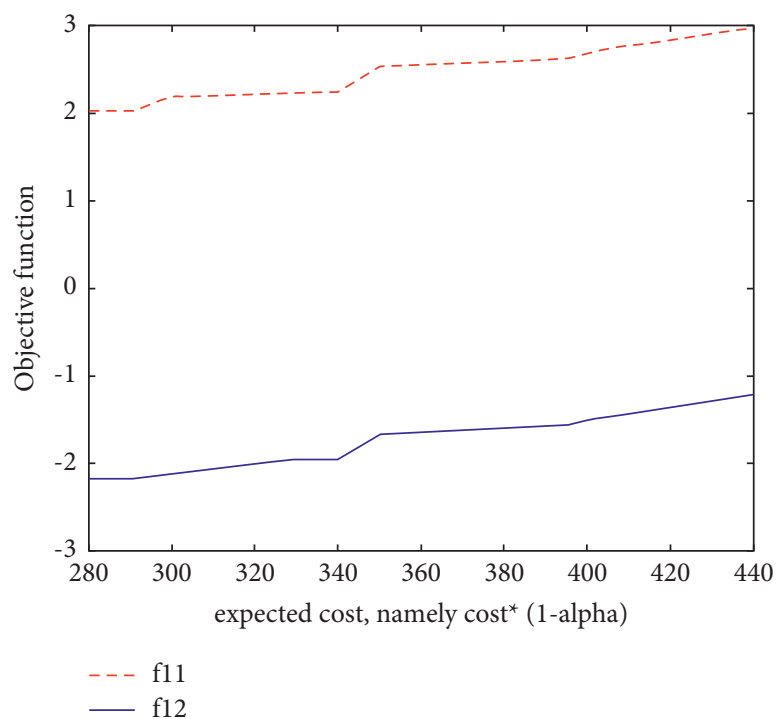

Figure 3: Parameter sensitivity of M-1. 


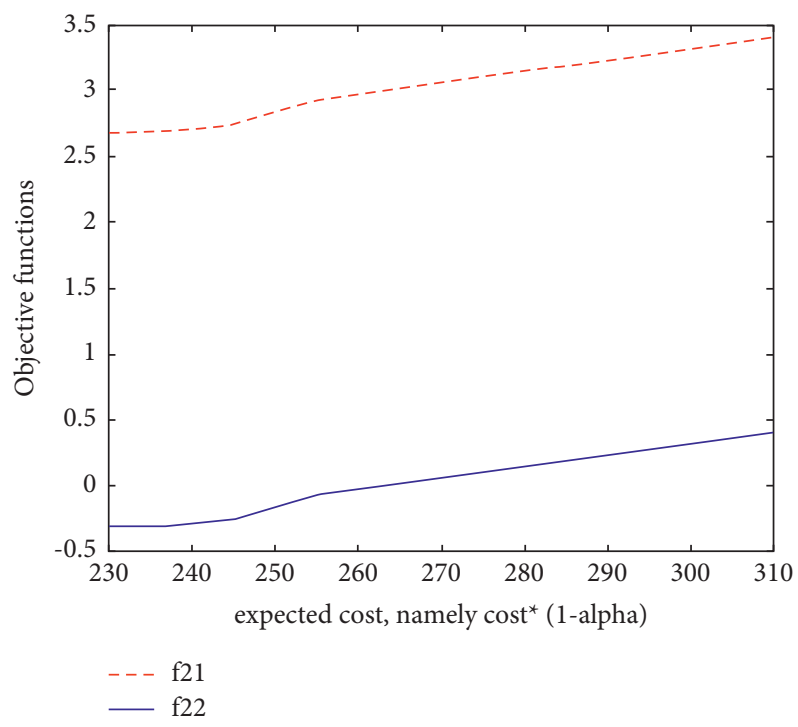

Figure 4: Parameter sensitivity of M-2.

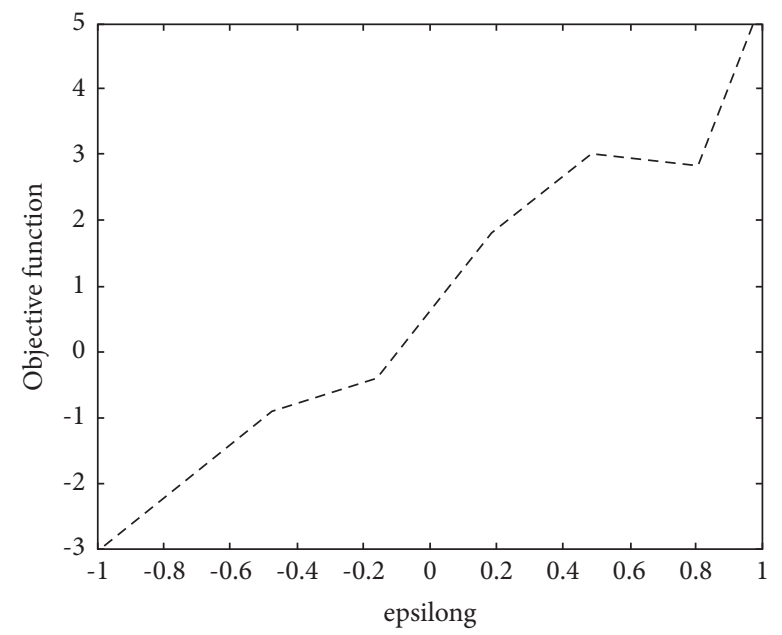

FIgURe 5: Randomness analysis of M-3.

TABle 4: Solutions of M-1.

\begin{tabular}{lccccccccc}
\hline \multirow{2}{*}{ Weight } & \multicolumn{2}{c}{ Objective functions } & \multicolumn{4}{c}{ Main manufacturer } \\
& $f_{1}^{1}$ & $f_{2}^{1}$ & $x_{1}^{1}$ & $x_{2}^{1}$ & $x_{3}^{1}$ & $x_{4}^{1}$ & $x_{5}^{1}$ & $x_{6}^{1}$ & $x_{7}^{1}$ \\
\hline$(1,1)$ & 2.24 & -1.95 & 0 & 1 & 1 & 0 & 1 & 1 \\
$(1.05,0.950)$ & 2.24 & -1.95 & 0 & 1 & 1 & 0 & 1 & 1 \\
\hline
\end{tabular}

TABle 5: Solutions of M-2.

\begin{tabular}{lcccccc}
\hline \multirow{2}{*}{ Weight } & \multicolumn{2}{c}{ Objective functions } & \multicolumn{3}{c}{ Supplier } \\
& $f_{1}^{2}$ & $f_{2}^{2}$ & $x_{1}^{2}$ & $x_{2}^{2}$ & $x_{3}^{2}$ & $x_{4}^{2}$ \\
\hline$(1,1)$ & 2.92 & -0.08 & 1 & 1 & 1 & 0 \\
$(0.95,1.05)$ & 2.92 & -0.08 & 1 & 1 & 1 & 0 \\
\hline
\end{tabular}


TABLE 6: Solutions of M-3.

\begin{tabular}{|c|c|c|c|c|c|c|c|c|c|c|c|c|c|c|c|c|}
\hline \multirow{2}{*}{ Weight } & \multicolumn{3}{|c|}{ Objective functions } & \multirow[b]{2}{*}{$x_{1}^{1}$} & \multicolumn{6}{|c|}{ Main manufacturer } & \multicolumn{5}{|c|}{ Supplier } & \multirow[b]{2}{*}{$\varepsilon$} \\
\hline & $f_{1}$ & $f_{2}$ & $f_{3}$ & & $x_{2}^{1}$ & $x_{3}^{1}$ & $x_{4}^{1}$ & $x_{5}^{1}$ & $x_{6}^{1}$ & $x_{7}^{1}$ & $x_{1}^{2}$ & $x_{2}^{2}$ & $x_{3}^{2}$ & $x_{4}^{2}$ & $x_{5}^{2}$ & \\
\hline$(1,1,1)$ & 1.11 & -1.73 & -0.32 & 1 & 1 & 0 & 1 & 0 & 1 & 1 & 0 & 1 & 1 & 0 & 1 & \\
\hline$(0.7,0.15,1.15)$ & 1.12 & -2.01 & -0.32 & 1 & 1 & 0 & 0 & 1 & 1 & 1 & 0 & 1 & 1 & 1 & 1 & 0.05 \\
\hline$(1.5,0.85,0.65)$ & 1.25 & -2.57 & -0.81 & 1 & 1 & 0 & 0 & 1 & 0 & 1 & 0 & 1 & 0 & 1 & 1 & \\
\hline
\end{tabular}

\section{Conclusion}

In this research, the problems on characterization and optimization of large aircraft supply chain resilience have been addressed. Based on the "main manufacturer-supplier" mode adopted by the large aircraft supply chain, a bilateral grey QFD supply chain resilience measurement model is constructed, considering the cooperation between the two roles. According to the output of the measurement model, resilience optimization models of the main manufacturer and the supplier are constructed without considering the synergy effect under the cost constraint. Moreover, the optimization model of the entire supply chain is constructed considering the synergy effect. Using the model proposed by this paper, the main manufacturer and suppliers can realize the influence of the cooperation uncertainty between them on the supply chain resilience and explore the way to achieve a win-win situation. Compared with the existing literature, we obtained some creative conclusions:

(1) The synergy between the main manufacturers and suppliers can not only improve resilience of the whole supply chain, but also reduce their own competitiveness and resilience, respectively. Therefore, in the process of decision-making, the main manufacturer and suppliers should pursue the maximum cooperation on the basis of ensuring their own interests, so as to achieve win-win situation.

(2) The sensitivity analysis shows that the cost of supply chain has a great impact on the resilience of the main manufacturers and suppliers, respectively, and both of them should formulate a reasonable cost plan according to their own actual situation.

(3) The sensitivity analysis shows that the uncertainty of cooperation between the main manufacturers and suppliers can significantly affect the resilience of the whole supply chain; that is, a benign cooperative relationship can effectively improve the overall resilience; on the contrary, it can reduce the overall elasticity.

To the best of our knowledge, our contribution could be concluded as follows: (1) A new perspective of supply chain resilience measurement is proposed. Most of the existing studies on the measurement of supply chain resilience are from the perspective of the entire supply chain. Considering the special "main manufacturer-supplier" organization mode of the large aircraft supply chain, this paper measures the supply chain resilience from the perspective of both sides. (2) A more practical optimization model is proposed in this paper. The model considers the effect of cooperation uncertainty between the main manufacturer and suppliers on the overall resilience of the supply chain, which is closer to the actual situation.

Our research is not free from limitations. First, some data in this paper are subjectively given, and the problem of personal orientation contained in the data may affect the results of the model to some extent. Second, we use the kernel of grey number to replace the grey number in the objective function to obtain the maximum value of the model. The maximum value of the model may be obtained using other better ways. Despite the limitations of this research, the method and model proposed in this paper can be applied to other supply chain application scenarios, which have a certain practical significance. Based on this, further research can be done: When the cooperation matrix elements measure the degree of cooperation uncertainty between the respective measures of the main manufacturer and suppliers, a more refined resilience measurement and optimization model can be constructed. The resilience measurement and optimization model considering the satisfaction of the main manufacturer and the suppliers can be built.

\section{Data Availability}

The date that support the findings of this study are available from third party. Restrictions apply to the availability of these data, which were used under license for this study. Data are available from the authors with the permission of third party.

\section{Conflicts of Interest}

The authors declare that they have no conflicts of interest.

\section{Acknowledgments}

This work was supported by the National Natural Science Foundation of China (no. 72071106 and no. 71502073) and the Humanities and Social Science Foundation of Ministry of Education (no. 17YJA790027).

\section{References}

[1] Y. Duan, C. Hofer, and J. A. Aloysius, "Consumers care and firms should too: on the benefits of disclosing supplier monitoring activities," Journal of Operations Management, vol. 67, no. 3, pp. 360-381, 2021.

[2] Y. Dong, K. Skowronski, S. Song, S. Venkataraman, and F. Zou, "Supply base innovation and firm financial performance," Journal of Operations Management, vol. 66, no. 7-8, pp. 768-796, 2020. 
[3] A. Brintrup, Y. Wang, and A. Tiwari, "Supply networks as complex systems: a network-science-based characterization," IEEE Systems Journal, vol. 11, no. 4, pp. 2170-2181, 2015.

[4] L. C. Johnsen, G. Voigt, and J. Weimann, "The effect of communication media on information sharing in supply chains," Production and Operations Management, vol. 29, no. 3, pp. 705-724, 2020.

[5] I. Heckmann, T. Comes, and S. Nickel, "A critical review on supply chain risk - definition, measure and modeling," Omega, vol. 52, pp. 119-132, 2015.

[6] K. M. K. Raghunath and S. L. T. Devi, "Supply chain risk management," International Journal of Information Systems and Supply Chain Management, vol. 11, no. 3, pp. 87-104, 2018.

[7] S. A. Melnyk, D. J. Closs, and S. E. Griffis, "Understanding supply chain resilience," Supply Chain Management Review, vol. 18, no. 1, pp. 35-41, 2014.

[8] E. Brandon-Jones, B. Squire, C. W. Autry, and K. J. Petersen, "A contingent resource-based perspective of supply chain resilience and robustness," Journal of Supply Chain Management, vol. 50, no. 3, pp. 55-73, 2014.

[9] Z. J. M Shen and Y. Q Sun, "Strengthening supply chain resilience during COVID-19:A case study of JD.com," Journal of Operations Management, pp. 1-25, 2021.

[10] M. A. Cohen and P. Kouvelis, "Revisit of AAA excellence of global value chains: robustness, resilience, and realignment," Production and Operations Management, vol. 30, no. 3, pp. 633-643, 2021.

[11] G. Behzadi, M. J. O’Sullivan, and T. L. Olsen, "On metrics for supply chain resilience," European Journal of Operational Research, vol. 287, no. 1, pp. 145-158, 2020.

[12] Y. Kim, Y.-S. Chen, and K. Linderman, "Supply network disruption and resilience: a network structural perspective," Journal of Operations Management, vol. 33-34, no. 1, pp. 43-59, 2015.

[13] M. Xu, X. Wang, and L. Zhao, "Predicted supply chain resilience based on structural evolution against random supply disruptions," International Journal of Systems Science: Operations \& Logistics, vol. 1, no. 2, pp. 105-117, 2014.

[14] Y.-K. Lin, C.-F. Huang, and C.-T. Yeh, "Network reliability with deteriorating product and production capacity through a multi-state delivery network," International Journal of Production Research, vol. 52, no. 22, pp. 6681-6694, 2014.

[15] M. D. Garvey, S. Carnovale, and S. Yeniyurt, "An analytical framework for supply network risk propagation: a Bayesian network approach," European Journal of Operational Research, vol. 243, no. 2, pp. 618-627, 2015.

[16] K. S. Anoop, D. Saurav, and S. S. Mahapatra, "Evaluation of performance index in resilient supply chain: a fuzzy-based approach," Benchmark: An. International Journal, vol. 24, no. 1, pp. 118-142, 2017.

[17] S. M. Lee and J. S. Rha, "Ambidextrous supply chain as A dynamic capability: building A resilient supply chain," Management Decision, vol. 54, no. 1, pp. 2-23, 2016.

[18] Q. Zhu, H. Krikke, and M. Caniëls, "Collaborate or not? A system dynamics study on disruption recovery," Industrial Management \& Data Systems, vol. 116, no. 2, pp. 271-290, 2016.

[19] P. Mensah and Y. Merkuryev, "Developing a resilient supply chain," Procedia - Social and Behavioral Sciences, vol. 110, pp. 309-319, 2014.

[20] J. Wang, R. R. Muddada, H. Wang et al., “Toward A resilient holistic supply chain network system: concept, review and future direction," IEEE Systems Journal, vol. 10, no. 2, pp. $410-421,2016$.

[21] G. Büyüközkan and G. Çifçi, "An integrated qfd framework with multiple formatted and incomplete preferences: a sustainable supply chain application," Applied Soft Computing, vol. 13, no. 9, pp. 3931-3941, 2013.

[22] R. John, A. Smith, S. Chotipanich, and M. Pitt, "Awareness and effectiveness of quality function deployment (QFD) in design and build projects in Nigeria," Journal of Facilities Management, vol. 12, no. 1, pp. 72-88, 2014.

[23] Y. Liu, J. Zhou, and Y. Chen, "Using fuzzy non-linear regression to identify the degree of compensation among customer requirements in QFD," Neurocomputing, vol. 142, no. 1, pp. 115-124, 2014.

[24] Z. Sener, E. Ozturk, and E. Ozturk, “A QFD-based decision model for ship selection in maritime transportation," International Journal of Innovation, Management and Technology, vol. 6, no. 3, pp. 202-205, 2015.

[25] F. B. Kurtulmuşoğlu and F. Pakdil, "Combined analysis of service expectations and perceptions in lodging industry through quality function deployment," Total Quality Management and Business Excellence, vol. 28, no. 11-12, pp. 1393-1413, 2017.

[26] V. Lapinskiene and V. Motuziene, "Integrated building design technology based on quality functiondeployment and axiomatic design methods: a case study," Sustainable Cities and Society, vol. 65, Article ID 102631, 2021.

[27] X. Wu and H. Liao, "Customer-oriented product and service design by a novel quality function deployment framework with complex linguistic evaluations," Information Processing \& Management, vol. 58, no. 2, Article ID 102469, 2021.

[28] S. Marinello, F. Lolli, and R. Gamberini, "An open innovation B2B web platform design: application of the QFD approach for the definition of its primary functions," International Journal of Product Development, vol. 25, no. 3, pp. 255-282, 2021.

[29] P. Akkawuttiwanich and P. Yenradee, "Fuzzy QFD approach for managing SCOR performance indicators," Computers \& Industrial Engineering, vol. 122, pp. 189-201, 2018.

[30] L. Osiro, F. R. Lima-Junior, and L. C. R. Carpinetti, “A group decision model based on quality function deployment and hesitant fuzzy for selecting supply chain sustainability metrics," Journal of Cleaner Production, vol. 183, pp. 964-978, 2018.

[31] K. G. D. Prasad, K. V. Subbaiah, and K. N. Rao, “Aligning the competitive strategy with supply chain strategy through QFD," Journal of Advances in Management Research, vol. 9, no. 2, pp. 189-198, 2016.

[32] M. Tavana, M. Yazdani, and D. Di Caprio, "An application of an integrated ANP-QFD framework for sustainable supplier selection," International Journal of Logistics Research and Applications, vol. 20, no. 3, pp. 254-275, 2017.

[33] M. Yazdani, P. Zarate, A. Coulibaly, and E. K. Zavadskas, “A group decision making support system in logistics and supply chain management," Expert Systems with Applications, vol. 88, pp. 376-392, 2017.

[34] A. Raj and S. K. Srivastava, "Sustainability performance assessment of an aircraft manufacturing firm," Benchmarking: An International Journal, vol. 25, no. 5, pp. 1500-1527, 2018.

[35] A. Ghadge, G. Karantoni, A. Choudhury, and A. Srinivasan, "Impact of additive manufacturing on aircraft supply chain performance: A system dynamics approach," Social Science Electronic Publishing, vol. 4, 2018. 
[36] A. Hendalianpour, "Optimal lot-size and price of perishable goods: a novel game-theoretic model using double interval grey numbers," Computers \& Industrial Engineering, vol. 149, Article ID 106780, 2020.

[37] J. Du, S. Liu, and Y. Liu, "A novel grey multi-criteria threeway decisions model and its application," Computers \& Industrial Engineering, vol. 158, Article ID 107405, 2021.

[38] S. Rahman, N. U. I. Hossain, K. Govindan, F. Nur, and M. Bappy, "Assessing cyber resilience of additive manufacturing supply chain leveraging data fusion technique: a model to generate cyber resilience index of a supply chain," CIRP Journal of Manufacturing Science and Technology, vol. 35, pp. 911-928, 2021.

[39] C.-T. Chang, "A technique of the salient success and survival aspiration levels for multiple objective/criteria decisionmaking problems," Journal of the Operational Research Society, vol. 69, no. 12, pp. 1957-1965, 2018. 